\title{
Cardiovascular health and sleep disturbances in two population-based cohort studies
}

Citation for published version (APA):

Hausler, N., Lisan, Q., Van Sloten, T., Haba-Rubio, J., Perier, M-C., Thomas, F., Danchin, N., Guibout, C., Boutouyrie, P., Heinzer, R., Jouven, X., Marques-Vidal, P., \& Empana, J-P. (2019). Cardiovascular health and sleep disturbances in two population-based cohort studies. Heart, 105(19), 1500-1506. https://doi.org/10.1136/heartjnl-2018-314485

Document status and date:

Published: 01/10/2019

DOI:

10.1136/heartjnl-2018-314485

Document Version:

Publisher's PDF, also known as Version of record

Document license:

Taverne

Please check the document version of this publication:

- A submitted manuscript is the version of the article upon submission and before peer-review. There can be important differences between the submitted version and the official published version of record.

People interested in the research are advised to contact the author for the final version of the publication, or visit the DOI to the publisher's website.

- The final author version and the galley proof are versions of the publication after peer review.

- The final published version features the final layout of the paper including the volume, issue and page numbers.

Link to publication

\footnotetext{
General rights rights.

- You may freely distribute the URL identifying the publication in the public portal. please follow below link for the End User Agreement:

www.umlib.nl/taverne-license

Take down policy

If you believe that this document breaches copyright please contact us at:

repository@maastrichtuniversity.nl

providing details and we will investigate your claim.
}

Copyright and moral rights for the publications made accessible in the public portal are retained by the authors and/or other copyright owners and it is a condition of accessing publications that users recognise and abide by the legal requirements associated with these

- Users may download and print one copy of any publication from the public portal for the purpose of private study or research.

- You may not further distribute the material or use it for any profit-making activity or commercial gain

If the publication is distributed under the terms of Article $25 \mathrm{fa}$ of the Dutch Copyright Act, indicated by the "Taverne" license above, 


\title{
Cardiovascular health and sleep disturbances in two population-based cohort studies
}

\author{
Nadine Hausler, ${ }^{\oplus}$ Quentin Lisan, ${ }^{\oplus 2,3,4}$ Thomas Van Sloten, $^{2,3,5}$ Jose Haba-Rubio, ${ }^{6}$ \\ Marie-Cécile Perier, ${ }^{2,3}$ Frédérique Thomas, ${ }^{7}$ Nicolas Danchin, ${ }^{\oplus, 7,8}$ \\ Catherine Guibout, ${ }^{2,3}$ Pierre Boutouyrie, ${ }^{2,9,10}$ Raphael Heinzer, ${ }^{6}$ Xavier Jouven, ${ }^{2,3,8}$ \\ Pedro Marques-Vidal, ${ }^{1}$ Jean-Philippe Empana ${ }^{2,3}$
}

For numbered affiliations see end of article.

\section{Correspondence to}

Dr Quentin Lisan, Universite Paris Descartes, Paris 75270, France;

quentin.lisan@gmail.com

PM-V and J-PE contributed equally.

$\mathrm{NH}$ and QL contributed equally.

Received 16 November 2018 Revised 14 March 2019 Accepted 21 March 2019 Published Online First 8 April 2019

\section{ABSTRACT \\ Objective We aimed to investigate the association between cardiovascular health ( $\mathrm{CVH})$, as defined by the American Heart Association, and several sleep disturbances.}

Methods Two community-based cohorts, the Paris Prospective Study 3 (PPS3, France, $n=6441$ ) and the CoLaus study (Switzerland, $n=2989$ ) were analysed. $\mathrm{CVH}$ includes 7 metrics which all can be classified as poor, intermediate and ideal. Global CVH score was categorised into poor (0-2 ideal metrics), intermediate (3-4 ideal metrics) and ideal ( $\geq 5$ ideal metrics). Associations between global CVH and self-reported sleep disturbances (proxy of sleep-disordered breathing [SDB], excessive daytime sleepiness, insomnia symptoms and short/long sleep duration) and SDB severity measured by polysomnography (PSG) were investigated. Adjusted OR/ relative risk ratio (RRR) and $95 \%$ Cls were estimated. Subjects with previous cardiovascular disease were excluded.

Results Compared with poor $\mathrm{CVH}$, subjects with intermediate and ideal global CVH had lower odds of self-reported SDB in both cohorts (ORs 0.55; $95 \% \mathrm{Cl} 0.44$ to 0.68 and $0.35 ; 95 \% \mathrm{Cl} 0.22$ to 0.53 , respectively) and had lower SDB severity measured by PSG (RRR 0.07; 95\% Cl 0.02 to 0.20) in CoLaus. Subjects with intermediate and ideal global CVH had lower odds of excessive daytime sleepiness in PPS3 (ORs 0.82; 0.72 to 0.95 and $0.80 ; 0.82$ to 1.02 , respectively). No consistent associations were found between $\mathrm{CVH}$ and sleep duration or insomnia symptoms.

Conclusions Higher levels of $\mathrm{CVH}$ are associated with lower odds of SDB and excessive daytime sleepiness. However, causal interpretation cannot be made and associations might be bidirectional.

\section{INTRODUCTION}

The prevalence of sleep disturbances, such as sleep-disordered breathing (SDB, 23\% in women and $50 \%$ in men), ${ }^{1}$ excessive daytime sleepiness (EDS, 20\%), ${ }^{2}$ insomnia $(17 \%)^{3}$ and short or long sleep durations $(35 \%),{ }^{4}$ is increasing in the population. ${ }^{35}$ These sleep disturbances have been linked to poor quality of life, ${ }^{6}$ increased risk of dementia ${ }^{7}$ and cardiovascular disease (CVD), and higher mortality. ${ }^{8-10}$ Therefore, identifying modifiable risk factors for sleep disturbances is of public health relevance.
Single cardiovascular risk factors have been associated with several sleep disturbances. ${ }^{10} 11$ However, most studies considered single cardiovascular risk factors, although they usually cluster and have an additive effect. The association between clustered cardiovascular risk factors and sleep disturbances remains unclear. Furthermore, most prior studies focused on associations between cardiovascular risk factors and a single sleep disturbance, precluding to help define whether a common or a specific sleep disturbance prevention strategy should be recommended.

The American Heart Association (AHA) has recently re-emphasised the concept of primordial prevention, that is, the prevention of cardiovascular risk factors onset. Hence, the AHA developed the Life's Simple 7, a 7-item tool including four behavioural and three biological metrics to define poor, intermediate and ideal cardiovascular health $(\mathrm{CVH}) .^{12}$ The importance of $\mathrm{CVH}$ has been demonstrated by several population-based studies reporting substantial and graded risk reductions in mortality and incident CVD for subjects with intermediate and ideal CVH compared with those with poor CVH. ${ }^{13-16}$ Given that sleep disturbances and CVD share some common risk factors, we hypothesised that higher $\mathrm{CVH}$ would be related to lower risk of sleep disturbances. Therefore, using two large contemporary community-based European studies, we quantified the association of $\mathrm{CVH}$ with several sleep disturbances.

\section{METHODS \\ Study population}

Details are described in the online supplementary methods.

\section{Paris Prospective Study 3}

The Paris Prospective Study 3 (PPS3) (Paris, France) is a prospective observational population-based cohort study on novel determinants of the main phenotypes of CVD. ${ }^{17}$ Between 2008 and 2012, 10157 men and women aged 50-75 years were recruited in a preventive medical centre. The standard health check-up included a complete clinical examination including measurement of height, weight and blood pressure, coupled with standard biological tests after an overnight fast. A self-administered questionnaire provided information related 
to sleep habits, lifestyle (tobacco and alcohol consumption, physical activity, diet), personal and family medical history and current health status.

\section{The CoLaus study}

This is a Swiss population-based observational prospective study investigating determinants of CVD. ${ }^{18}$ Between 2003 and 2006, 6733 subjects (age range 35-75 years) were included from a random sample of the population of Lausanne, Switzerland. The first follow-up of the cohort (median follow-up time 5.4 years) included 5064 subjects. Subjects underwent a physical examination after an overnight fasting and responded to a questionnaire covering demographic and medical history, health behaviours and sleep quality measures.

\section{Cardiovascular health}

The AHA criteria were used to define the level of each metric and global $\mathrm{CVH}$ was categorised as poor, intermediate and ideal to reflect $0-2,3-4$ and 5-7 metrics at ideal. ${ }^{12}$ Similarly, behavioural CVH (smoking, body mass index [BMI], diet and physical activity) was categorised as poor, intermediate and ideal to reflect $0-1,2$ and 3-4 behavioural metrics at the ideal level; biological $\mathrm{CVH}$ (hypertension, total cholesterol and fasting blood glucose) was categorised as poor, intermediate and ideal to reflect to $0-1,2$ and 3 metrics at the ideal level (online supplementary methods and table 1$).^{12}$

In sensitivity analysis (see below), global CVH was examined as a continuous variable considering (1) the number of metrics at ideal level (from 0 to 7 ) and (2) a global CVH score, calculated by assigning 0 point for each metric at poor level, 1 point for metric at intermediate level and 2 points for metric at ideal level (ranging from 0 to 14 ). ${ }^{12}$

\section{Sleep quality measures}

Sleep-disordered breathing

In both cohorts, a proxy including the main risk factors for SDB was used to measure SDB. ${ }^{19}$ Participants reporting to snore at least 1-2 times per week (in CoLaus) or to snore regularly or often (in PPS3) and being male and/or being at least 55 years old and/or having a BMI $\geq 30 \mathrm{~kg} / \mathrm{m}^{2}$ and/or having hypertension and/or having EDS were considered to have SDB (online supplementary table 2).

In CoLaus, a subset of the study population underwent polysomnography (PSG). ${ }^{1}$ SDB was objectively measured, calculated as the average number of apnoea/hypopnoea per hours of sleep (apnoea-hypopnoea index, $[\mathrm{AHI}]$ ), and categorised as normal (AHI 0-4), mild (AHI 5-14), moderate (AHI 15-29) and severe (AHI $\geq 30$ ) according to the American Academy of Sleep Medicine. ${ }^{20}$

\section{Excessive daytime sleepiness}

EDS was assessed using the Epworth Sleepiness Scale (ESS) in both cohorts. ${ }^{21}$ EDS was defined by an ESS $\geq 11$. $^{21}$

\section{Sleep duration}

In both cohorts, sleep duration was extracted from the Pittsburgh Sleep Quality Index. ${ }^{22}$ Subjects reported their average hours of sleep per night during the last month. Sleep duration was categorised into short ( $\leq 6$ hours/night), normal (6-9 hours/ night) and long ( $\geq 9$ hours/night).

\section{Insomnia symptoms}

Insomnia symptoms were measured using questions from the Pittsburgh Sleep Quality Index. Insomnia symptoms were considered present (yes/no) when subjects reported difficulties initiating sleep and difficulties maintaining sleep or early morning awakening 3-4 times per week.

\section{Confounders}

In PPS3, depression score was assessed using the 13-item Questionnaire of Depression second version, Abridged. ${ }^{23}$ Depressive status (yes/no) was defined by a score $\geq 7$. In CoLaus, depressive status was measured with the validated 20-item Center for Epidemiologic Studies-Depression Scale questionnaire, and depressive status was considered for a score $\geq 17$ for men and 23 for women. ${ }^{24}$ Education level was categorised as low (no graduation in PPS3, mandatory education or apprenticeship in CoLaus), intermediate (high school diploma) and high (university diploma). We categorised alcohol consumption as never/less than daily, 1-2 glasses per day and $\geq 3$ glasses per day. A medical doctor checked the use of medications during a face-to-face interview in PPS3. In CoLaus, subjects self-reported the use of prescribed and over the counter medications.

\section{Exclusion criteria}

Participants were excluded from the analyses if they had (1) previous history of CVD; (2) missing data on more than one $\mathrm{CVH}$ metric; (3) missing data on any sleep variables or (4) missing data on any covariates.

\section{Statistical analyses}

Statistical analyses were performed using R V.3.3.3 for PPS3 ( www.r-project.org) and STATA V.15.1 for CoLaus (StataCorp).

\section{Single cohort analyses}

The association between global CVH (main exposure) and binary sleep disturbances (outcomes), that is, proxy for SDB, EDS and insomnia symptoms were examined by logistic regressions for each cohort and prevalence ratios (to be considered as an OR) were obtained. The association between $\mathrm{CVH}$ and SDB measured by PSG (four categories) and sleep duration (three categories, with 6-9 hours/night as the reference) was quantified by multinomial logistic regressions and relative risk ratios were estimated. Regression models adjusted for age, sex, education, living alone status, depression, use of sleep medications and alcohol consumption. Further, the same analyses were performed using behavioural and biological $\mathrm{CVH}$ as independent variables (secondary exposure).

\section{Pooled data cohort analyses}

Mixed-effects regressions models with random effects for the cohort were used. Logistic mixed models were used for binary outcomes (proxy for SDB, EDS and insomnia symptoms), whereas linear mixed models were used for sleep duration considered here as a continuous outcome (the normality distribution of the model's residuals was graphically checked). Pooled data analyses were adjusted for the same covariates as for the single cohort analysis. As for the single cohort analysis, global $\mathrm{CVH}$ but also behavioural and biological $\mathrm{CVH}$ were examined.

\section{Sensitivity analyses}

First, subjects with missing data on any $\mathrm{CVH}$ metrics were excluded. Second, the adapted $\mathrm{CVH}$ metric diet was measured by all available metrics in each cohort (additionally including 


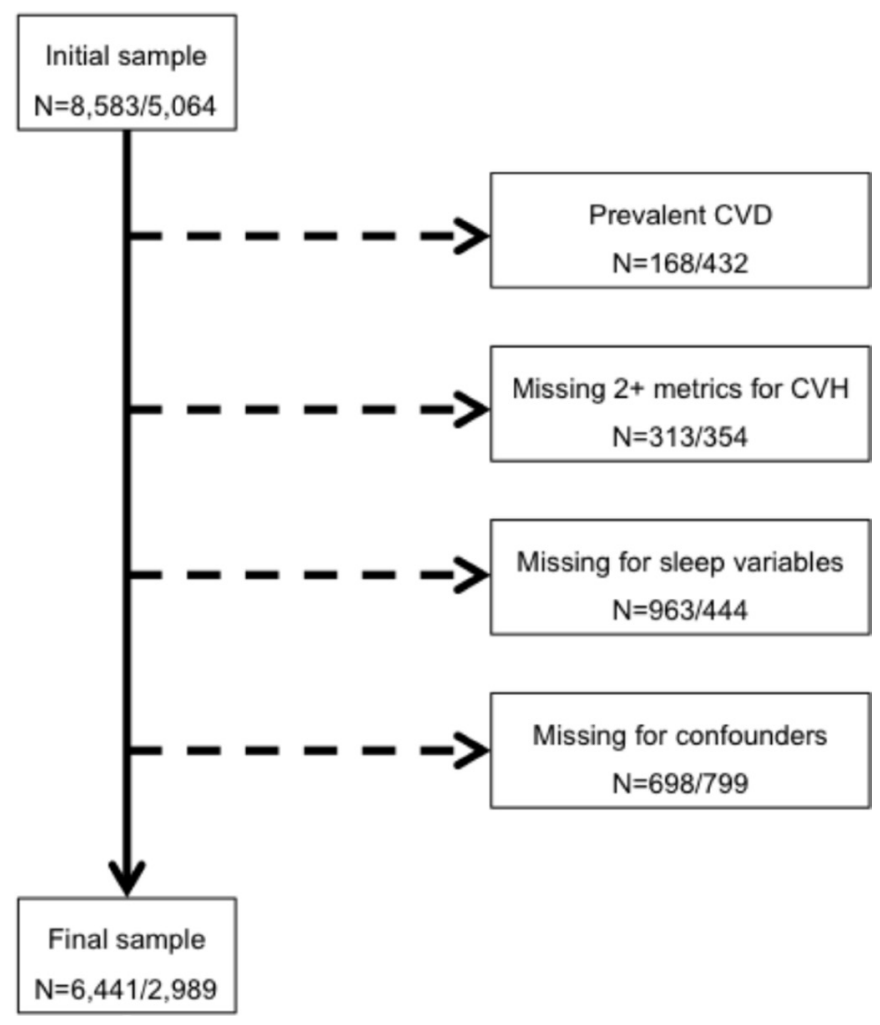

Figure 1 Selection procedure, Paris Prospective Study 3 (France) and CoLaus (Switzerland). Numbers are for Paris Prospective Study 3/CoLaus. CVD, cardiovascular disease; CVH, cardiovascular health.

sodium in PPS3 and fibre in CoLaus) and time since smoking cessation was taken into account for the smoking status in PPS3. Third, the association between $\mathrm{CVH}$ and each sleep disturbance was further mutually adjusted for the other three sleep disturbances. Fourth, CVH was measured as a continuous variable considering either the number of metrics at the ideal level (0-7) or the CVH score as defined above (ranging from 0 to 14). Next, to limit collinearity, BMI and hypertension were excluded from the definition of $\mathrm{CVH}$ and sex was not adjusted for, when estimating its related odds for a proxy for SDB (containing BMI, hypertension and sex in its definition). In this sensitivity analysis, poor, intermediate and ideal CVH corresponded to $0-2$, 3, 4-5 metrics at ideal level. Lastly, we assessed the relationship between global $\mathrm{CVH}$ and sleep duration measured by PSG in CoLaus.

\section{RESULTS}

\section{Study population}

From 8583 participants in PPS3 who answered the sleep questionnaires and from the 5064 subjects participating in follow-up 1 in CoLaus, respectively, 6441 and 2989 participants were free of previous CVD and had full data (figure 1). Out of the 2989 subjects in CoLaus, 1404 had PSG data. The characteristics of excluded and included participants are compared in online supplementary table 3 .

\section{Prevalence of sleep disturbances and bivariate association with CVH}

As presented in table 1, ideal CVH was present in 9.5\% (PPS3) and $11.2 \%$ (CoLaus) of the participants. In both cohorts, participants with ideal CVH were more frequently women, had a higher educational level, were more frequently living alone and drank less alcohol. Proxy for SDB was present in 33\% (PPS3) and $20 \%$ (CoLaus) of the participants, and decreased with an increasing level of global CVH in both cohorts $(p<0.001)$. In CoLaus, the prevalence of moderate/severe SDB measured by PSG was 35\% and decreased with an increasing level of global $\mathrm{CVH}(\mathrm{p}<0.001)$. EDS was present in $17 \%$ (PPS3) and $11 \%$ (CoLaus) of the participants and decreased with increasing level of global CVH in PPS3 $(p=0.02)$ but not in CoLaus $(p=0.41)$. Insomnia symptoms were present in $14.4 \%$ (PPS3) and $7 \%$ (CoLaus) of the participants, and decreased with increasing level of global CVH in CoLaus $(p=0.07)$ but not in PPS3 $(p=0.18)$. There were $25 \%$ and $8 \%$ of the participants sleeping 6 hours or less per night in PPS3 and CoLaus, respectively; and 5.1\% and $1.3 \%$ sleeping 9 hours or more per night in each cohort. There was no clear pattern between the distribution of short/long sleep duration and global CVH level.

\section{Association of CVH and sleep disturbances: single cohort analysis \\ $\mathrm{CVH}$ and SDB}

As presented in figure 2, in multivariable logistic regression analysis, the odds for proxy for SDB gradually decreased in subjects with intermediate and ideal levels of global CVH compared with subjects with poor $\mathrm{CVH}$ in both cohorts $(\mathrm{p}<0.001$ in both cohorts). There was a stronger inverse gradient between higher global CVH and the severity of SDB measured by PSG in a subsample of CoLaus $(\mathrm{p}<0.001$, table 2$)$.

These inverse associations with either the proxy for SDB (figure 2) or SDB measured by PSG in the subsample of CoLaus (table 2) were observed for the behavioural and biological $\mathrm{CVH}$.

\section{CVH and EDS}

In PPS3, subjects with intermediate and ideal global CVH had lower odds of EDS compared with subjects with poor CVH while no association was found in CoLaus (figure 2).

In both cohorts, subjects with intermediate and ideal levels of behavioural $\mathrm{CVH}$ had lower odds of EDS, when compared with subjects with poor $\mathrm{CVH}$, although the association with ideal behavioural $\mathrm{CVH}$ was borderline significant in CoLaus $(p=0.08)$. Conversely, in both cohorts, subjects with higher biological CVH had higher odds of EDS; however, these associations were statistically significant only for subjects with ideal compared with poor biological CVH in CoLaus.

\section{$\mathrm{CVH}$, insomnia symptoms and sleep duration}

In both cohorts, no consistent associations were found between $\mathrm{CVH}$ and both and insomnia symptoms and sleep duration (online supplementary table 4).

\section{Pooled analysis}

Results of the pooled analysis are reported in table 3. The odds for SDB remained significant, being 0.62 (95\% CI 0.56 to 0.68 ) and 0.41 (95\% CI 0.33 to 0.49$)$ for intermediate and ideal global $\mathrm{CVH}$ when compared with poor global $\mathrm{CVH}$, respectively. The odds for EDS became significant, being 0.87 (95\% CI 0.77 to 0.99 ) and 0.80 (95\% CI 0.65 to 0.98$)$ for intermediate and ideal global CVH, respectively. As for the single cohort analysis, there was no significant association between intermediate and ideal global CVH and insomnia or sleep duration.

\section{Sensitivity analyses}

Effect size and direction of the association between global CVH and sleep disturbances were consistent with those obtained in 
Table 1 Characteristics of the study participants according to cardiovascular health status, Paris Prospective Study 3 (PPS3) (France, $n=6441$ ) and CoLaus (Switzerland, $\mathrm{n}=2989$ )

\begin{tabular}{|c|c|c|c|c|}
\hline & Cardiovascular health & & & \\
\hline & Poor & Intermediate & Ideal & $P$ value \\
\hline PPS3 & $\mathrm{n}=3007(46.7)$ & $\mathrm{n}=2820(43.8)$ & $\mathrm{n}=614(9.5)$ & \\
\hline \multicolumn{5}{|l|}{ Sleep complaints } \\
\hline Sleep-disordered breathing (proxy) & $1206(40.1)$ & $780(27.7)$ & $117(19.1)$ & $<0.001$ \\
\hline Excessive daytime sleepiness & $547(18.2)$ & $440(15.6)$ & $94(15.3)$ & 0.02 \\
\hline Insomnia symptoms & $411(13.7)$ & $422(15.0)$ & $99(16.1)$ & 0.18 \\
\hline Sleep duration (hours per night) & & & & 0.27 \\
\hline$\leq 6$ & $845(28.1)$ & $773(27.4)$ & $162(26.4)$ & \\
\hline $6-9$ & $1990(66.2)$ & $1917(68.0)$ & $422(68.2)$ & \\
\hline$\geq 9$ & $172(6.7)$ & $130(4.6)$ & $30(4.9)$ & \\
\hline \multicolumn{5}{|l|}{ General characteristics } \\
\hline Male gender & $2244(74.6)$ & $1600(56.7)$ & $271(44.1)$ & $<0.001$ \\
\hline Age (years) & $59.3 \pm 6.02$ & $59.3 \pm 6.21$ & $59.2 \pm 6.13$ & 0.84 \\
\hline Education level & & & & 0.01 \\
\hline Low & $851(28.3)$ & $704(25.0)$ & $152(24.8)$ & \\
\hline Intermediate & $566(18.8)$ & $517(18.3)$ & $103(16.8)$ & \\
\hline High & $1590(52.9)$ & $1599(56.7)$ & $359(58.4)$ & \\
\hline Living alone & $598(19.9)$ & $672(23.8)$ & $158(25.7)$ & $<0.001$ \\
\hline Alcohol (drinks per day) & & & & $<0.001$ \\
\hline Never & $469(8.2)$ & $314(11.1)$ & $98(16.0)$ & \\
\hline $1-2$ & $2229(74.1)$ & $2246(79.6)$ & $485(79.0)$ & \\
\hline$\geq 3$ & $532(17.7)$ & $260(19.2)$ & $31(5.1)$ & \\
\hline Depressive status & $232(7.7)$ & $211(7.5)$ & $40(6.5)$ & 0.59 \\
\hline Sleep medications & $275(9.1)$ & $296(10.5)$ & $64(10.4)$ & 0.20 \\
\hline CoLaus & $\mathrm{n}=1383(46.3)$ & $\mathrm{n}=1272(42.5)$ & $\mathrm{n}=334(11.2)$ & \\
\hline \multicolumn{5}{|l|}{ Sleep complaints } \\
\hline Sleep-disordered breathing (proxy) & $392(28.3)$ & $176(13.8)$ & $27(8.1)$ & $<0.001$ \\
\hline \multicolumn{5}{|l|}{ Severity of OSA (from PSG data) } \\
\hline No & $94(14.7)$ & $225(37.4)$ & $97(58.8)$ & $<0.001$ \\
\hline Mild & $230(36.1)$ & $227(37.8)$ & $45(27.3)$ & \\
\hline Moderate & $171(26.8)$ & $96(16)$ & $19(11.5)$ & \\
\hline Severe & $143(22.4)$ & $53(8.8)$ & $4(2.4)$ & \\
\hline Excessive daytime sleepiness & $142(10.3)$ & $150(11.8)$ & $34(10.2)$ & 0.41 \\
\hline Insomnia symptoms & $110(8.0)$ & $80(6.3)$ & $16(4.8)$ & 0.07 \\
\hline Sleep duration (hours per night) & & & & 0.08 \\
\hline$\leq 6$ & $124(9.0)$ & $97(7.6)$ & $18(5.4)$ & \\
\hline $6-9$ & $1236(89.4)$ & $1163(91.4)$ & $313(93.7)$ & \\
\hline$\geq 9$ & $23(1.7)$ & $12(0.9)$ & $3(0.9)$ & \\
\hline \multicolumn{5}{|l|}{ General characteristics } \\
\hline Male gender & $881(63.7)$ & $502(39.5)$ & $104(31.1)$ & $<0.001$ \\
\hline Age (years) & $59.0 \pm 9.8$ & $55.0 \pm 9.7$ & $50.8 \pm 8.3$ & $<0.001$ \\
\hline Education & & & & $<0.001$ \\
\hline Low & $744(53.8)$ & $538(42.3)$ & $128(38.3)$ & \\
\hline Intermediate & $363(26.2)$ & $380(29.9)$ & $82(24.6)$ & \\
\hline High & $276(20.0)$ & $354(27.8)$ & $124(37.1)$ & \\
\hline Living alone & $515(37.2)$ & $576(45.3)$ & 139 (41.6) & $<0.001$ \\
\hline Alcohol (drinks per day) & & & & $<0.001$ \\
\hline Never & $226(16.3)$ & $290(22.8)$ & $100(29.9)$ & \\
\hline $1-2$ & $1107(80.0)$ & $964(75.8)$ & $233(69.8)$ & \\
\hline$\geq 3$ & $50(3.6)$ & $18(1.4)$ & $1(0.3)$ & \\
\hline Depressive status & $175(12.7)$ & $158(12.4)$ & $34(10.2)$ & 0.46 \\
\hline Sleep medications & $186(13.5)$ & $140(11.0)$ & $36(10.8)$ & 0.11 \\
\hline
\end{tabular}

Numbers are $\mathrm{N}(\%)$ or mean $\pm S D$ deviation. $P$ values are from Pearson $X^{2}$ or ANOVA where appropriate and refer to the global comparison across the three groups. ANOVA, analysis of variance; OSA, obstructive sleep apnoea; PSG, polysomnography. 


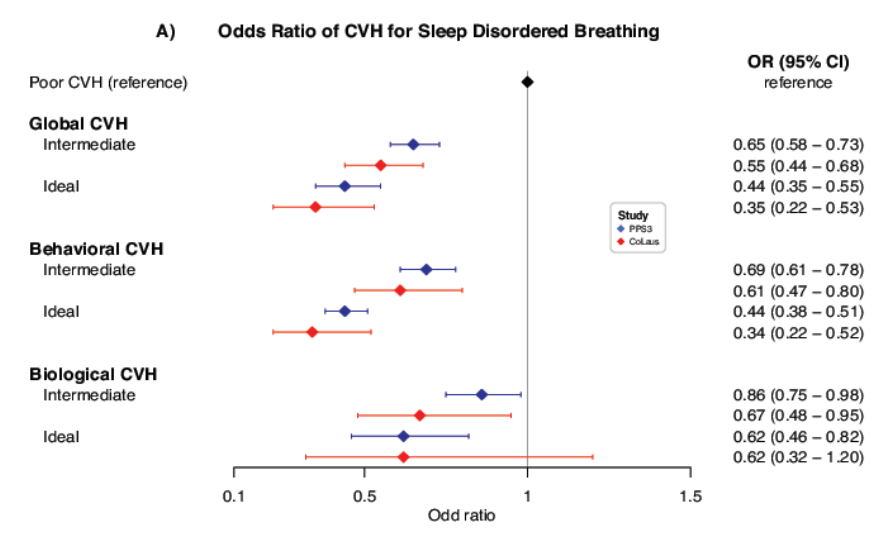

B)
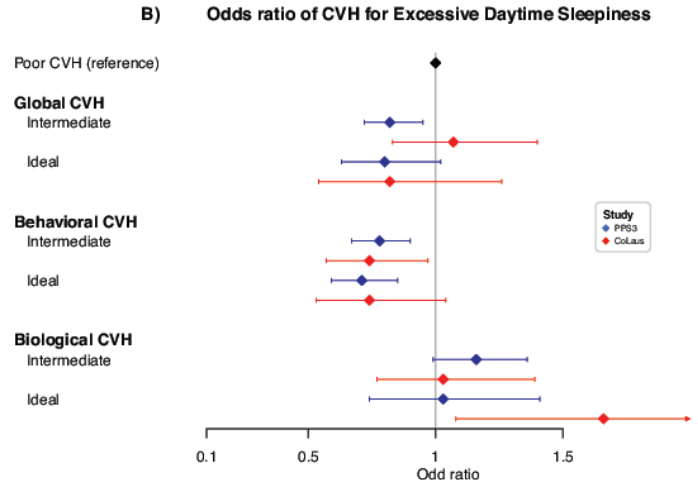

OR (95\% Cl)

reference

$0.82(0.72-0.95)$

$1.07(0.83-1.40)$

$0.80(0.63-1.02)$

$0.82(0.54-1.26)$

$0.78(0.67-0.90)$

$0.74(0.57-0.97)$

$0.74(0.53-1.04)$

$1.16(0.99-1.36)$

$1.03(0.77-1.39)$

$1.03(0.74-1.41)$

$1.66(1.08-2.54)$

Figure 2 Association of global, behavioural and biological cardiovascular health with sleep-disordered breathing and excessive daytime sleepiness, Paris Prospective Study 3 (France) and CoLaus (Switzerland). Multivariable analysis conducted using logistic regression; results are expressed as $\mathrm{OR}$ and $95 \% \mathrm{Cl}$. CVH, cardiovascular health.

main analyses in both cohorts (online supplementary table 5 and figure 1).

\section{DISCUSSION}

In two large European population-based studies, higher global, behavioural and biological $\mathrm{CVH}$ were consistently associated with lower odds of SDB, and higher behavioural CVH was related to lower odds of EDS compared with subjects with poor $\mathrm{CVH}$. In addition, there was some evidence for an association between higher levels of $\mathrm{CVH}$ and lower odds for short/long sleep duration. Conversely, $\mathrm{CVH}$ was not related to insomnia symptoms.

The distribution of ideal CVH was in the same range in PPS3 (9.5\%) and CoLaus (11.2\%). In addition, the distribution of sociodemographic characteristics across the levels of CVH was exactly the same in both cohorts. However, there was some difference in the distribution of sleep disturbances between the two studies, in particular regarding the proxy for SDB or short and long sleep duration, although sleep disturbances definitions have been harmonised as much as possible. Notwithstanding these differences, associations between $\mathrm{CVH}$ and sleep disturbances were consistent in PPS3 and CoLaus, reinforcing the robustness of the findings.

\section{CVH and SDB}

Although several cross-sectional studies have related to single cardiovascular risk factors with $\mathrm{SDB},{ }^{125}$ none investigated the combined association of cardiovascular risk factors as measured by CVH and SDB. In both PPS3 and CoLaus, the combination of several risk factors at intermediate or ideal compared with poor levels was associated with a reduced likelihood of having the proxy for SDB (up to $45 \%$ and $65 \%$, respectively). The gradual relationships between $\mathrm{CVH}$ and SDB were even stronger when the severity of SDB was objectively evaluated using PSG in CoLaus. Thus, the proxy for SDB is a rather conservative measure for SDB and accordingly, it underestimated the prevalence of SDB in CoLaus by $15 \%$ when compared with SDB measured by PSG. Finally, these evidences were found for both the behavioural and biological CVH. All these aspects emphasise the validity of the reported association between CVH and SDB. In addition, SDB has been shown to be a contributor to the onset of some of the CVH metrics such as diabetes, dyslipidaemia, hypertension ${ }^{10}$ and obesity. ${ }^{26}$ It is, therefore, likely that the association between CVH and SDB is bidirectional.

Table 2 Results of multinomial logistic regression between severity of SDB as measured by polysomnography and global, behavioural and biological CVH in CoLaus (Switzerland, $\mathrm{n}=1404$ )

\begin{tabular}{|c|c|c|c|}
\hline & \multicolumn{3}{|c|}{ Severity of SDB (no=ref) } \\
\hline & Mild & Moderate & Severe \\
\hline & $\operatorname{RRR~}(95 \% \mathrm{Cl})$ & $\operatorname{RRR}(95 \% \mathrm{Cl})$ & $\operatorname{RRR}(95 \% \mathrm{Cl})$ \\
\hline \multicolumn{4}{|l|}{ Global CVH } \\
\hline Poor & 1 & 1 & 1 \\
\hline Intermediate & 0.52 (0.38 to 0.72$)$ & $0.37(0.25$ to 0.53$)$ & 0.29 (0.19 to 0.46$)$ \\
\hline Ideal & $0.27(0.17$ to 0.42$)$ & $0.20(0.11$ to 0.36$)$ & $0.07(0.02$ to 0.20$)$ \\
\hline \multicolumn{4}{|l|}{ Behavioural CVH } \\
\hline Poor & 1 & 1 & 1 \\
\hline Intermediate & 0.59 (0.42 to 0.81$)$ & $0.43(0.29$ to 0.62$)$ & 0.38 (0.25 to 0.58$)$ \\
\hline Ideal & $0.39(0.27$ to 0.57$)$ & 0.22 (0.14 to 0.37$)$ & 0.17 (0.09 to 0.31$)$ \\
\hline \multicolumn{4}{|l|}{ Biological CVH } \\
\hline Poor & 1 & 1 & 1 \\
\hline Intermediate & 0.64 (0.46 to 0.87 ) & 0.51 (0.34 to 0.77$)$ & 0.33 (0.19 to 0.57 ) \\
\hline Ideal & $0.27(0.15$ to 0.49$)$ & $0.30(0.14$ to 0.65$)$ & 0.13 (0.03 to 0.58$)$ \\
\hline
\end{tabular}

Models were adjusted for age, sex, education, living alone status, depression, use of sleep medications and alcohol consumption.

$\mathrm{CVH}$, cardiovascular health; ref, reference category; RRR, relative risk ratio; SDB, sleep-disordered breathing. 
Table 3 Results of mixed-effect regressions for the pooled analysis

\begin{tabular}{|c|c|c|c|c|}
\hline & \multirow{2}{*}{$\begin{array}{l}\text { SDB } \\
\text { OR }(95 \% \mathrm{Cl})\end{array}$} & \multirow{2}{*}{$\begin{array}{l}\text { EDS } \\
\text { OR }(95 \% \mathrm{Cl})\end{array}$} & \multirow{2}{*}{$\begin{array}{l}\text { Insomnia } \\
\text { OR }(95 \% \mathrm{Cl})\end{array}$} & \multirow{2}{*}{$\begin{array}{l}\text { Sleep duration } \\
\text { Regression coefficien } \\
(95 \% \mathrm{Cl})\end{array}$} \\
\hline & & & & \\
\hline \multicolumn{5}{|l|}{ Global CVH } \\
\hline Poor & 1 (reference) & 1 (reference) & 1 (reference) & 1 (reference) \\
\hline Intermediate & 0.62 (0.56 to 0.68 ) & 0.87 (0.77 to 0.99 ) & 0.89 (0.77 to 1.02 ) & $-0.02(-0.03$ to 0.06$)$ \\
\hline Ideal & 0.41 (0.33 to 0.49 ) & 0.80 (0.65 to 0.98 ) & 0.84 (0.67 to 1.06 ) & $0.08(-0.01$ to 0.16$)$ \\
\hline \multicolumn{5}{|c|}{ Behavioural CVH } \\
\hline Poor & 1 (reference) & 1 (reference) & 1 (reference) & 1 (reference) \\
\hline Intermediate & 0.66 (0.59 to 0.73 ) & 0.76 (0.67 to 0.87 ) & 1.01 (0.87 to 1.18 ) & $-0.003(-0.05$ to 0.05$)$ \\
\hline Ideal & 0.41 (0.36 to 0.47 ) & 0.72 (0.61 to 0.85$)$ & 0.93 (0.78 to 1.11 ) & 0.06 (0.001 to 0.13$)$ \\
\hline \multicolumn{5}{|l|}{ Biological CVH } \\
\hline Poor & 1 (reference) & 1 (reference) & 1 (reference) & 1 (reference) \\
\hline Intermediate & 0.82 (0.72 to 0.92 ) & 1.13 (0.98 to 1.30$)$ & 0.99 (0.84 to 1.16$)$ & $0.03(-0.02$ to 0.09$)$ \\
\hline Ideal & 0.62 (0.48 to 0.80$)$ & 1.21 (0.93 to 1.56$)$ & 0.64 (0.44 to 0.92 ) & $-0.03(-0.14$ to 0.08$)$ \\
\hline
\end{tabular}

ORs and regression coefficient were estimated by logistic and linear mixed-effect regressions adjusted for age, sex, education, living alone status, depression, use of sleep medications and alcohol consumption.

CVH, cardiovascular health; EDS, excessive daytime sleepiness; SDB, sleep-disordered breathing.

\section{CVH and EDS}

Only one small $(n=635)$ population-based study in rural Ecuador explored the potential relationship between global $\mathrm{CVH}$ and EDS and did not find any significant association. ${ }^{11}$ Conversely, in our study, using a much larger sample size, two independent European cohorts and additionally considering the behavioural and the biological components of $\mathrm{CVH}$, higher behavioural $\mathrm{CVH}$ in both cohorts were significantly associated with lower odds of EDS. This result is in line with previous studies that associated the presence of single cardiovascular risk factors belonging to behavioural CVH (ie, obesity) with EDS. ${ }^{27}$ However, the association between ideal biological $\mathrm{CVH}$ and higher prevalence of EDS in both cohorts was unexpected although not confirmed in the pooled analysis, and additional studies are required to clarify this finding.

\section{CVH and insomnia symptoms}

The lack of consistent association between $\mathrm{CVH}$ and insomnia symptoms in each study is in line with previous studies reporting no significant relationship between single behavioural cardiovascular risk factors - such as obesity, physical activity or smokingand insomnia symptoms. ${ }^{28}$ The present study further suggests the absence of the additive effect of seven cardiovascular risk factors on insomnia symptoms.

\section{CVH and sleep duration}

There was little evidence for an association between CVH and sleep duration. The relationship was neither gradual nor consistent between the two cohorts, and sensitivity analyses with objectively measured sleep duration did not indicate an association either.

\section{Implications}

The lower odds of SDB and EDS associated with CVH carry important public health implications owing to the burden of sleep disturbances in the population and the wide range of sleep-related health consequences. ${ }^{6-10}$ Importantly, the lower odds for both SDB and EDS were primarily driven by modifiable behavioural $\mathrm{CVH}$ that do not require pharmacological interventions. The results of our sensitivity analysis on $\mathrm{CVH}$ score suggest that gaining one additional metric at an ideal level is already associated with significantly reduced odds of SDB and, to a lesser extent, EDS. Hence, this approach might be more achievable than promoting to the population the attainment of an ideal global CVH to help preventing the onset of SDB and EDS.

\section{Study limitations}

First, as a cross-sectional analysis, causal interpretation cannot be made and associations might be bidirectional. Second, both cohorts are based on voluntary participation resulting in a possible over-representation of health aware subjects. Third, sleep disturbances, some cardiovascular risk factors and covariates were self-reported and thus prone to recall, misclassification and reporting bias. Fourth, the 7-item tool used to assess $\mathrm{CVH}$

\section{Key messages}

What is already known on this subject?

- Single cardiovascular risk factors are associated with sleep disturbances.

- Although cardiovascular risk factors usually cluster, their combined effect on sleep disturbances remains unknown.

\section{What might this study add?}

- In two population-based cohort studies, higher cardiovascular health-a cluster of modifiable cardiovascular risk factors defined by the American Heart Association-was associated with lower odds of self-reported and objectively measured sleep-disordered breathing (OR 0.35; 95\% Cl 0.22 to 0.53 ) and excessive daytime sleepiness (OR 0.82; $95 \% \mathrm{Cl}$ 0.72 to 0.95 ).

\section{How might this impact on clinical practice?}

- Given the high prevalence of sleep-disordered breathing and excessive daytime sleepiness in the population and their adverse health consequences, promoting higher cardiovascular health to prevent the development of risk factors associated with sleep-disordered breathing and excessive daytime sleepiness has the potential for important public health implications. 
assigns the same weights to each of the metric and further studies are required to refine the tool. Fifth, there were a few participants $(\mathrm{n}<30)$ by $\mathrm{CVH}$ group in some analyses of sleep disturbances, which may have contributed to the lack of statistical significance and wide CIs. Sixth, declustering the Life's Simple 7 into behavioural and biological CVH is likely to lower the statistical power of these subanalyses explaining why both subscales were considered as secondary exposures.

\section{CONCLUSIONS}

Higher levels of CVH were associated with lower odds of SDB and EDS. In addition to benefit on mortality and CVD risk, the current study suggests that higher $\mathrm{CVH}$ may have secondary benefit on highly prevalent sleep disturbances. Longitudinal and intervention studies are needed to support the promotion of $\mathrm{CVH}$ to prevent the development of risk factors associated with SDB and EDS.

\section{Author affiliations}

'Department of Medicine, Internal Medicine, Lausanne University Hospital (CHUV), Lausanne, Switzerland

${ }^{2}$ Universite Paris Descartes, Paris, France

${ }^{3}$ Paris Cardiovascular Research Center, Department of Epidemiology, INSERM, UMR-S970, Paris, France

${ }^{4}$ Department of Head and Neck surgery, Georges Pompidou European Hospital, AP-HP, Paris, France

${ }^{5}$ Cardiovascular Research Institute Maastricht and Department of Internal Medicine, Maastricht University Medical Centre, Maastricht, The Netherlands

${ }^{6}$ Center for Investigation and Research in Sleep (CIRS), Lausanne University Hospital (CHUV), Lausanne, Switzerland

${ }^{7}$ Preventive and Clinical Investigation Center, Paris, France

${ }^{8}$ Department of Cardiology, Georges PompidouEuropean Hospital, AP-HP, Paris, France

${ }^{9}$ Department of Pharmacology, Georges PompidouEuropean Hospital, AP-HP, Paris, France

${ }^{10}$ Paris Cardiovascular Research Center, Department of Arterial Mechanics, INSERM, UMR-S970, Paris, France

Contributors Acquisition, analysis or interpretation of data: QL, NH, PM-V and J-PE. Drafting of the manuscript: QL and NH. Critical revision of the manuscript for important intellectual content: All authors.Statistical analysis: QL and NH. Obtained funding: $X J, J-P E, P B, J H-R, P M-V$ and RH. Administrative, technical or material support: JH-R, FT, ND, PB, PM-V, XJ and J-PE.

Funding The PPS3 Study was supported by grants from The National Research Agency (ANR), the Research Foundation for Hypertension (RFHTA), the Research Institute in Public Health (IRESP) and the Region lle de France (Domaine d'Intérêt Majeur). The CoLaus study was and is supported by research grants from GlaxoSmithKline, the Faculty of Biology and Medicine of Lausanne and the Swiss National Science Foundation (grants 33CSCO-122661, 33CS30-139468, 33CS30148401 and grant 320030E-176280).

Competing interests None declared.

Patient consent for publication Obtained.

Ethics approval The study protocol was approved by the Ethics Committee of the Cochin Hospital (Paris, France) and Institutional Ethics Committee of the University of Lausanne (references 16/03 and 33/09).

Provenance and peer review Not commissioned; externally peer reviewed.

\section{REFERENCES}

1 Heinzer R, Vat S, Marques-Vidal P, et al. Prevalence of sleep-disordered breathing in the general population: the HypnoLaus study. Lancet Respir Med 2015;3:310-8.

2 Whitney CW, Enright PL, Newman AB, et al. Correlates of daytime sleepiness in 4578 elderly persons: the Cardiovascular Health Study. Sleep 1998;21:27-36.
3 Garland SN, Rowe H, Repa LM, et al. A decade's difference: 10-year change in insomnia symptom prevalence in Canada depends on sociodemographics and health status. Sleep Health 2018:4:160-5.

4 Liu Y, Wheaton AG, Chapman DP, et al. Prevalence of healthy sleep duration among adults--United States, 2014. MMWR Morb Mortal Wkly Rep 2016;65:137-41.

5 Peppard PE, Young T, Barnet JH, et al. Increased prevalence of sleep-disordered breathing in adults. Am J Epidemiol 2013;177:1006-14.

6 Baldwin CM, Griffith KA, Nieto FJ, et al. The association of sleep-disordered breathing and sleep symptoms with quality of life in the Sleep Heart Health Study. Sleep 2001:24:96-105.

7 Hung CM, Li YC, Chen HJ, et al. Risk of dementia in patients with primary insomnia: a nationwide population-based case-control study. BMC Psychiatry 2018;18:38.

8 He Q, Zhang P, Li G, et al. The association between insomnia symptoms and risk of cardio-cerebral vascular events: A meta-analysis of prospective cohort studies. Eur J Prev Cardiol 2017;24:1071-82.

9 Empana JP, Dauvilliers Y, Dartigues JF, et al. Excessive daytime sleepiness is an independent risk indicator for cardiovascular mortality in community-dwelling elderly: the three city study. Stroke 2009;40:1219-24.

10 Grandner MA, Alfonso-Miller P, Fernandez-Mendoza J, et al. Sleep: important considerations for the prevention of cardiovascular disease. Curr Opin Cardiol 2016:31:551-65.

11 Del Brutto OH, Mera RM, Zambrano M, et al. Excessive daytime somnolence and cardiovascular health: a population-based study in rural ecuador. Sleep Sci 2014;7:186-8.

12 Lloyd-Jones DM, Hong Y, Labarthe D, et al. Defining and setting national goals for cardiovascular health promotion and disease reduction: the American Heart Association's strategic impact goal through 2020 and beyond. Circulation 2010;121:586-613.

13 Yang Q, Cogswell ME, Flanders WD, et al. Trends in cardiovascular health metrics and associations with all-cause and CVD mortality among US adults. JAMA 2012;307:1273-83.

14 Folsom AR, Yatsuya $H$, Nettleton JA, et al. Community prevalence of ideal cardiovascular health, by the American Heart Association definition, and relationship with cardiovascular disease incidence. J Am Coll Cardiol 2011;57:1690-6.

15 Gaye B, Canonico M, Perier M-C, et al. Mortality, and vascular events in elderly subjects: the three-city study. J Am Coll Cardiol 2017;69:3015-26.

16 Samieri C, Perier MC, Gaye B, et al. Association of cardiovascular health level in older age with cognitive decline and incident dementia. JAMA 2018;320:657-64.

17 Empana JP, Bean K, Guibout C, et al. Paris prospective study III: a study of novel heart rate parameters, baroreflex sensitivity and risk of sudden death. Eur J Epidemiol 2011;26:887-92.

18 Firmann M, Mayor V, Vidal PM, et al. The CoLaus study: a population-based study to investigate the epidemiology and genetic determinants of cardiovascular risk factors and metabolic syndrome. BMC Cardiovasc Disord 2008;8:6.

19 Lisan Q, Tafflet M, Charles MA, et al. Self-reported body silhouette trajectories across the lifespan and excessive daytime sleepiness in adulthood: a retrospective analysis. The paris prospective study III. BMJ Open 2018;8:e020851.

20 Berry RB, Budhiraja R, Gottlieb DJ, et al. Rules for scoring respiratory events in sleep: update of the 2007 AASM manual for the scoring of sleep and associated events. Deliberations of the sleep apnea definitions task force of the american academy of sleep medicine. J Clin Sleep Med 2012;8:597-619.

21 Johns MW. A new method for measuring daytime sleepiness: the Epworth sleepiness scale. Sleep 1991;14:540-5.

22 Buysse DJ, Reynolds CF, Monk TH, et al. The pittsburgh sleep quality index: a new instrument for psychiatric practice and research. Psychiatry Res 1989;28:193-213.

23 Pichot P. A self-report inventory on depressive symptomatology (QD2) and its abridged form (QD2): Assessment of Depression, 1986:108-22.

24 Fuhrer R, Rouillon F. The French version of the CES-D (Center for Epidemiologic Studies-Depression Scale). Eur Psychiatry 1989:4:163-6.

25 Shahar E, Whitney CW, Redline S, et al. Sleep-disordered breathing and cardiovascular disease: cross-sectional results of the Sleep Heart Health Study. Am J Respir Crit Care Med 2001;163:19-25.

26 Brown MA, Goodwin JL, Silva GE, et al. The Impact of Sleep-Disordered Breathing on Body Mass Index (BMI): The Sleep Heart Health Study (SHHS). Southwest J Pulm Crit Care 2011;3:159-68.

27 Bixler EO, Vgontzas AN, Lin HM, et al. Excessive daytime sleepiness in a general population sample: the role of sleep apnea, age, obesity, diabetes, and depression. J Clin Endocrinol Metab 2005:90:4510-5.

28 LeBlanc M, Mérette C, Savard J, et al. Incidence and risk factors of insomnia in a population-based sample. Sleep 2009:32:1027-37. 